\title{
$\ddot{A} \boldsymbol{h}$
}

\section{Entre médicos y abogados: disputas en torno a las enfermedades profesionales en Argentina, 1900-1915}

\author{
[Between Physicians and Lawyers: \\ Disputes Regarding Occupational Diseases in Argentina, 1900-1915]
}

\author{
Pablo Daniel Maddalena \\ (Instituto de Altos Estudios Sociales / \\ Universidad Nacional de San Martín, Argentina) \\ pdmaddalena@yahoo.com.ar
}

\begin{abstract}
Resumen
El presente artículo repara en la forma en que se fue constituyendo el concepto de enfermedad profesional en Argentina, hasta el momento de la sanción de la ley de accidentes de trabajo de 1915 en la cual se la contempló. En ese recorrido será posible identificar las tensiones que existieron dentro de las agencias estatales con atribuciones para regular las relaciones laborales. Indagar en las producciones del Departamento Nacional de Higiene y su par de Trabajo, permitirá dilucidar el camino trazado por la disciplina del derecho para erigirse como espacio decisorio a la hora de dirimir sobre las enfermedades profesionales, aún a expensas de otros campos profesionales como el médico que, per se, contaba con saberes peculiares de su disciplina.
\end{abstract}

Palabras claves: Enfermedades Profesionales; Riesgos Laborales; Medicina del Trabajo; Argentina; Estado.

\begin{abstract}
This article takes note of how the concept of occupational disease was gradually built in Argentina, up to the moment when the Workers Compensation Act was passed in 1915, covering accidents at work, which included occupational diseases. During that period, it is possible to identify the tensions that existed within government agencies with power to regulate work relations. Delving into the productions of the National Department of Hygiene and of Labor, it will be possible to elucidate the path laid down by the discipline of law to become a decision-making space when deciding about occupational diseases, yet at the expense of other professional fields, such as the medical, which already had knowledge incidental to the discipline.
\end{abstract}

Keywords: Occupational Diseases; Occupational Risks; Labour Medicine; Argentina; State.

Recibido: 20/03/2020

Evaluación: 28/04/2020

Aceptado: 20/05/2020

Anuario de la Escuela de Historia Virtual - Año 11 - N 18 - 2020: pp. 229-250.

ISSN: 1853-7049

http://revistas.unc.edu.ar/index.php/anuariohistoria 


\section{Entre médicos y abogados: disputas en torno a las enfermedades profesionales en Argentina, 1900-1915}

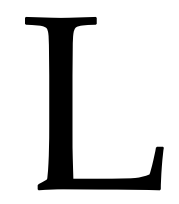

a ley de accidentes de trabajo y enfermedades profesionales $\mathrm{N}^{\circ} 9.688$, que se promulgó en Argentina en el año 1915, tuvo la finalidad de establecer el marco jurídico por el cual aquellos trabajadores que sufrían un deterioro de la salud como producto del ejercicio de su labor debían ser indemnizados. Esta norma, pionera en el país en materia de seguridad social, se erigió sobre dos componentes centrales: por un lado, resarcir al trabajador lesionado físicamente mientras desarrollaba una tarea para un tercero. Por el otro, reparar las enfermedades profesionales que ocasionaba el ambiente laboral. Mientras el primer aspecto resultó más tangible, las definiciones acerca de lo que se entendía por enfermedad profesional fueron algo difusas, provocando disputas políticas en las que también se pusieron en juego las atribuciones que iban adquiriendo las diferentes esferas estatales, algunas de ellas recientemente creadas. No obstante, ya los expertos (Morresi y Vommaro, 2011) ${ }^{1}$ de fines del siglo XIX y principios del XX consolidaron la idea de la existencia de "trabajos que enferman", y que producían perjuicios a la salud de los trabajadores, pero también a su moral y su intelecto.

Este trabajo se ocupa de recorrer uno de los caminos por los cuales el derecho, en su rol de lenguaje administrativo del Estado, se afianzó como resorte del arbitraje en las relaciones laborales, ya desde las postrimerías del siglo XIX. Si bien la primacía del derecho como elemento legitimador de la intervención estatal se tornó indiscutible a medida que transcurrieron los años del novecientos, fue para las décadas que actuaron de bisagra al cambio de siglo cuando las preocupaciones manifiestas de la "cuestión social" hicieron que el pensamiento jurídico se orientase a considerar una faceta social. De acuerdo con Eduardo Zimmermann (2013), ello estaba emparentado con una ampliación de los alcances del derecho nacional, en la medida que se producía una separación respecto de la mirada clásica del pensamiento jurídico basada en la idea liberal, por la cual, el derecho público se oponía al derecho individualista.

En sincronía con las transformaciones que vivenciaba el derecho en su trayectoria hacia el normativismo de lo público, el conocimiento jurídico entró en una competencia con otros campos disciplinares por ser la voz cantante en el armado regulatorio sobre los accidentes de trabajo. Este artículo parte del interés por construir la manera en la cual la especialidad del derecho procuró apropiarse de objetos que a priori podrían considerarse

\footnotetext{
${ }^{1}$ Siguiendo a Morresi y Vommaro (2011, p. 14), por experto se entiende a quien detenta "formas de intervención en el campo del poder y de la producción de bienes materiales y simbólicos que remiten a un saber técnicamente fundado, ligado a una disciplina científica o a un campo profesional."
} 
peculiares de otras áreas de saberes. Las disputas entre abogados y médicos por determinar los grados de las lesiones padecidas por los trabajadores accidentados, o por precisar si las enfermedades de los obreros se vinculaban con la labor desarrollada, estuvieron a la vanguardia de las tensiones entre ambas profesiones. Fue el derecho el que se arrogó la construcción de un lenguaje propio desde donde impuso su autoridad para reservarse el espacio decisorio a la hora de dirimir sobre accidentes laborales, necesitando, pero a la vez subsumiendo, las opiniones de médicos, higienistas, ingenieros, a definiciones conceptuales provenientes del mundo jurídico. No obstante, esa prevalencia del derecho distó de ser reflejo de un camino lineal y estuvo estrechamente emparentada a las agencias estatales en las cuales cada disciplina encontró mayor enraizamiento, lo que marcaba un afianzamiento del lenguaje jurídico que, aún sin incumbencias profesionales que se impusieran per se a las de otros ámbitos de saber, se apropiaron de la validación de opiniones sobre problemas del mundo laboral. Para avanzar en ese sentido se indagarán fundamentalmente las publicaciones e investigaciones que se generaron en el Departamento Nacional de Higiene (DNH) y en su par de Trabajo (DNT), en tanto espacios institucionales que se convirtieron en agentes activos en la caracterización de la cuestión social en la Argentina de la época (González Leandri y Suriano, 2017, p. 19).

La historiografía reparó desde distintas perspectivas en la manera en la cual el Estado atendió las contingencias que emanaban de una sociedad que, desde las últimas décadas del siglo XIX, se transformaba a pasos agigantados y originaba debates que contribuyeron a precisar lo que se entendió como parte de la "cuestión social" en Argentina. Mientras algunos planteos pusieron el énfasis en el accionar de las elites "liberales reformistas" como las promotoras de las primeras políticas sociales (Zimmermann, 1995), otro grupo de estudios se abocó a demostrar que la conflictividad social de la época amalgamó la conformación de instituciones estatales y la sanción de las leyes atentas a las problemáticas obreras (Panettieri, 1984; Isuani, 1985; Suriano, 2000; Lobato y Suriano, 2014).

Las políticas sociales, entendidas como acciones públicas destinadas a proteger a los trabajadores frente a determinados riesgos, encuentran en los ámbitos estatales un espacio casi exclusivo para su diseño y puesta en práctica (Golbert, 2010). Por ello, es preciso posicionar el trabajo respecto a cómo analizar al Estado, para lo cual se retoman ciertas propuestas formuladas por Theda Skocpol (1989), quien se refiere a la necesidad de pensar al brazo ejecutor del gobierno a partir de sus instituciones y desde sus cuerpos técnicos y políticos. Esa mirada implica alejarse de pensar al Estado como un ente omnipotente que acciona de modo monolítico y habilita, en cambio, a apreciar las voces variopintas y las tensiones que laten en su interior (Bohoslavsky y Soprano, 2010).

Durante la última década, la literatura académica produjo avances en el conocimiento de los accidentes de trabajo en Argentina desde una perspectiva sociohistórica. Victoria Haidar (2008) escudriñó en los saberes técnicos acumulados por el funcionariado nacional y demostró, a partir del concepto de la biopolítica foucaultiana, que la sanción de la ley $N^{\circ} 9.688$ operó como mecanismo de control sobre la salud de los trabajadores en la 
232 | Entre médicos y abogados: disputas en torno a las enfermedades profesionales...

búsqueda por conservar la fuerza laboral hasta alcanzar su óptimo rendimiento. Karina Ramacciotti (2014) aportó a la comprensión de las prácticas que se suscitaron en torno a la política social que gestionaba los riesgos del trabajo. A su vez, se realizaron contribuciones acerca del rol que le cupo a la justicia sobre los litigios por accidentes de trabajo en épocas de carencia de una legislación específica que regulase el asunto: por un lado, a través de la capacidad de los jueces para brindar una respuesta a la cuestión social (Schjolden, 2009); por otro lado, dilucidando que el funcionamiento de la justicia en materia de accidentes de trabajo operó como prolegómeno al surgimiento de un fuero laboral que se materializaría a mediados del siglo XX (Stagnaro, 2016). Otros estudios repararon en las acciones judiciales emprendidas por los trabajadores con la finalidad de demostrar su centralidad tanto en la construcción práctica de la legislación sobre accidentes de trabajo (Scheinkman, 2015) como en la prevalencia del sentido indemnizatorio de la ley $\mathrm{N}^{\circ}$ 9.688 por sobre los dispositivos preventivos en materia de reducción de riesgos laborales (Maddalena y Ramacciotti, 2019). Si bien tales lecturas resultan ineludibles para explorar la puesta en funcionamiento de los marcos regulatorios ante los casos de accidentes de trabajo, también insinuaron cuantiosos interrogantes desde una pluralidad de enfoques, que no hacen más que demostrar la centralidad de los riesgos laborales en lo concerniente a las relaciones del trabajo.

\section{Definiciones médicas y veredicto jurídico sobre las enfermedades profesionales}

A fines de mayo de 1902, los diputados de la Unión Cívica Nacional por la Capital, Belisario Roldán (hijo) y Marco Avellaneda, elevaron a la Cámara Baja el primer proyecto legislativo que tuvo por finalidad regular los casos de accidentes de trabajo y fijar los parámetros que debían regir las indemnizaciones en favor de los obreros. Esta presentación abría, en el ámbito parlamentario, un derrotero de más de una docena de años durante los cuales el Congreso de la Nación recibió más de diez proyectos para normar el asunto. El aspecto central de la propuesta de Roldán y Avellaneda estribó en insinuar un cambio en la concepción doctrinal del derecho que dejaba atrás la demostración de la culpa como basamento jurídico según lo establecía el Código Civil Argentino, y asumía que la realización de toda labor implicaba un riesgo que le era intrínseco, y que, en caso de que ese riesgo se convirtiera en accidente, la responsabilidad patronal era responder resarcitoriamente. ${ }^{2}$ Sin dudas, la jurisprudencia argentina sintió el efecto refractario de las transformaciones jurídicas que se daban en algunos países europeos, en particular en Francia, Alemania y España, en un camino que desembocaría en la aceptación de la doctrina del riesgo profesional como elemento rector en los fallos sobre accidentes laborales (Maddalena, 2019).

\footnotetext{
${ }^{2}$ La idea jurídica de que todo trabajo tenía un riesgo dio lugar a la doctrina del "riesgo profesional", en disputa con la doctrina de la "culpa", por la cual, era el obrero quien debía demostrar que el accidente padecido había sido responsabilidad patronal como paso previo al derecho indemnizatorio.
}

Anuario de la Escuela de Historia Virtual - Año 11 - No 18 - 2020: pp. 229-250. ISSN: 1853-7049 
El proyecto de ley presentado en 1902 definió accidente como sinónimo de lesión física sufrida por un obrero que se encontraba realizando un trabajo para un tercero. ${ }^{3}$ No hizo ninguna alusión a la cuestión de las enfermedades que podían originarse producto del trabajo. Los pocos juristas que analizaron la pertinencia de la norma llevada a consideración de la Cámara de Diputados en 1902 explicaron que esa escisión entre lesión física y enfermedad profesional, que dejaba a esta última fuera de la cobertura legal, se debía a que la propuesta de Roldán y Avellaneda había reproducido casi textualmente la ley de accidentes que en España se había sancionado en 1900 y que no contemplaba la protección en caso de enfermedades laborales.

Si el proyecto de Roldán y Avellaneda pretendió zanjar los inconvenientes que traían aparejados los riesgos laborales a partir de la adopción de una legislación foránea, es factible inferir que los ámbitos de producción legal se pretendieron, a priori, suficientes para proporcionar una respuesta al problema. Evadir los fundamentos técnicos que podían aportar a una mirada integral del tema se tradujo en una limitación de la trascendencia de la propuesta legislativa. Ello lo demuestra el alcance que tuvo el proyecto de Ley Nacional del Trabajo presentado al Parlamento en 1904 por el Ministro del Interior, Joaquín V. González. En lo concerniente a los accidentes de trabajo, fue allí la primera vez que se intentó establecer un marco legislativo que fijara el procedimiento indemnizatorio para el caso de las enfermedades acaecidas en el ambiente de trabajo. Para tal tarea, junto a doctores en jurisprudencia, se convocó a profesionales vinculados a la medicina entre quienes se destacaron Bialet Massé, José Ingenieros, Augusto Bunge, Carlos Malbrán, lo cual, como intentará demostrarse más adelante, coadyuvó a que la cuestión de las enfermedades laborales fuera puesta en escena.

En el tratamiento de los accidentes, uno de los aportes más vanguardistas del proyecto de González radicó en promover que las enfermedades provenientes de los trabajos desarrollados en las industrias debían ser indemnizadas con idéntico tenor a los casos de lesiones corporales. No obstante, la pretendida Ley Nacional del Trabajo no reparó en precisar cuáles eran las enfermedades que debían ser incluidas en los alcances de la aplicación de la norma, atribución que fue delegada al Poder Ejecutivo que debía reglamentar la situación. Aquí es admisible aseverar que la aceptación de la existencia de trabajos que producían enfermedades cobraba validez entre las elites políticas y técnicas, aunque las presiones que podía generar la información disponible hasta el momento aún no fueran suficientes para quebrantar la decisión política de no avanzar en legislar los accidentes de trabajo y menos aún de considerar a las enfermedades profesionales como un componente del riesgo laboral.

Más allá de las disputas en juego que inhibieron la sanción de la ley impulsada por Joaquín V. González, resulta necesario interrogarse acerca de cómo, por quiénes y desde qué ámbito, se concibió que las enfermedades adquiridas en consecuencia de la realización de un trabajo para un tercero debían originar un resarcimiento. En ese sentido, la

${ }^{3}$ Diario de Sesiones de la Cámara de Diputados (en adelante DSCD), Tomo I, 1902, p. 143. 
234 | Entre médicos y abogados: disputas en torno a las enfermedades profesionales...

generación de conocimiento por parte de la profesión médica tuvo una incidencia primordial. Pero existía una formulación previa del vínculo estrecho entre salubridad y ambiente sano de trabajo. Siguiendo a Ricardo González Leandri (2010, p. 64), esos lazos pueden rastrearse hasta las transformaciones que las epidemias, de cólera en 1867/1868 y de fiebre amarilla en 1871, generaron sobre las formas de vinculación entre las agencias estatales y la higiene pública. Desde fines de la década de 1870, y de la pluma de algunos de los primeros higienistas del país, aparecieron registros prematuros que destacaron los efectos del trabajo sobre la salud. Uno de los pioneros en tratar el influjo del ambiente laboral -refiriendo principalmente a las consecuencias emergentes de una industria incipiente- sobre la salud fue el médico Eduardo Wilde (1885), quien hizo hincapié en las condiciones de higiene y seguridad y en el impacto que el trabajo de ciertas ramas productivas tenía sobre la vida de los niños y las mujeres (Lobato, 2007; Nari, 2004; Biernat y Ramacciotti, 2013). Sin embargo, esos esbozos trazados por Wilde carecieron de una línea de continuidad sostenida en el tiempo, probablemente a causa de nuevas crisis que aquejaron a la medicina de fines del siglo XIX, como el brote de cólera que se propagó por el interior del país hacia 1886. De esta situación resulta posible inferir que los mecanismos estatales se abocaron fundamentalmente a poner en marcha dispositivos sanitarios para enfrentar los embates de enfermedades como el cólera, la fiebre amarrilla (Fiquepron, 2017; Galeano, 2009) o la tuberculosis (Armus, 2007, p. 276), dejando poco espacio para impeler estudios del vínculo salud-trabajo.

Retomando nuevamente a González Leandri es posible sostener que el DNH se erigió como la representación del reconocimiento institucionalizado de la corporación médica. A la vez, su brazo de difusión, los Anales del Departamento Nacional de Higiene (ANDH), a partir de su primer número de 1891, se consolidó como una plataforma de información sobre aspectos que se dirimían dentro del gobierno y de la propia profesión médica (González Leandri, 2017, pp. 34-35). En lo concerniente al mundo del trabajo, las preocupaciones de los miembros del DNH siguieron rondando el lugar de las mujeres y los niños en el proceso productivo y, durante la última década del siglo XIX, no repararon en forma particular sobre las enfermedades profesionales.

Una conjunción de variables torció el rumbo en el quehacer del DNH en relación a la salud de los trabajadores. Por un lado, en 1902 el médico Carlos Malbrán asumió la presidencia del organismo y, desde ese cargo, se empeñó en proporcionar un control sanitario sustentado en su expertise bacteriológica, a la vez que reforzó el perfil técnico del Departamento. Por el otro lado, el conflictivo clima social de los años circundantes al cambio de siglo demandó al DNH inmiscuirse en los aspectos laborales con técnicas que preludiaron la higiene industrial. Un tercer aspecto estuvo emparentado a la recepción de las ideas que circulaban en el ámbito internacional, que adquirieron mayor ahínco desde el cambio de siglo producto del maridaje existente entre los expertos y los espacios estatales, los cuales promovían la asistencia de su funcionariado a los ámbitos que en Europa debatían sobre la higiene social. Al mismo tiempo, otro elemento contribuyó a una comprensión más acabada del vínculo entre la salud y el trabajo, ya que el papel 
desempeñado por un grupo de médicos socialistas de destacada trayectoria política como fueron Juan B. Justo, Nicolás Repetto, Enrique Dickman y Augusto Bunge, le otorgó relevancia al tema promoviendo su debate público.

Augusto Bunge fue justamente quien, desde su función de médico incorporado al $\mathrm{DNH}$, tuvo un accionar destacado en demostrar los efectos de la insalubridad de ciertos trabajos e industrias. Su formación de médico especializado en higiene laboral y su matriz política e ideológica, le proporcionaron las herramientas necesarias para analizar la problemática de la salud de los trabajadores desde una perspectiva más amplia que la de sus colegas. Las preocupaciones de Bunge se tradujeron en un informe titulado $E l$ trabajo industrial en Buenos Aires, que respondió a las instrucciones dadas por Joaquín V. González, quien procuraba recopilar información para su proyecto de legislación laboral. Bunge describió en su estudio lo que habían documentado las inspecciones industriales del personal del DNH entre fines de 1903 y principios de 1904. Allí, se ocupó de analizar las problemáticas que traían los emplazamientos industriales en la urbe, donde, por ejemplo, las manufacturas de tabaco ocupaban zonas céntricas envenenando la atmósfera con sus emanaciones. En ese informe se retomaron y profundizaron cuestiones planteadas ya por los esbozos previos de la higiene industrial. Las relaciones entre higiene y volumen del ambiente, el uso del agua y los desagües, la disposición de baños y lugares para higiene personal, fueron variables que caracterizaron los lugares de trabajo analizados en función de las ramas industriales inspeccionadas. Bunge detectó peligros para la salud del obrero relacionados con los esfuerzos del trabajo muscular y los ambientes nocivos por la naturaleza infecciosa o tóxica de los materiales empleados, muchas veces manipulados directamente por los trabajadores. La producción de polvos irritantes o tóxicos, inhalados o depositados sobre la piel, se identificó con enfermedades del aparato respiratorio, o problemas de absorción (Bunge, 1904, pp. 346-362).

En su informe El trabajo industrial en Buenos Aires, Bunge fue crítico acerca de las posibilidades de mejoras que la sanción del proyecto de ley del ministro Joaquín V. González podía generar en las condiciones laborales. La ignorancia de las clases trabajadoras, a su entender, era el mayor obstáculo para la implementación de medidas preventivas de la propagación de accidentes y enfermedades profesionales. A su juicio, el avance del maquinismo, si bien ampliaba los peligros del trabajo, también potencialmente podía suprimir los riesgos, reemplazando al obrero en tareas insalubres o proporcionando dispositivos que lo resguardasen de las adversidades a que los enfrentaba su tarea (Bunge, 1904, p. 363). Bunge identificó los riesgos de determinadas industrias y las enfermedades que originaban en los trabajadores elementos químicos como el fósforo blanco y sus elevados niveles de toxicidad, o el enfisema pulmonar por el contagio bucal del soplado del vidrio. Además, realizó descripciones sobre cómo se llevaban a cabo los procesos productivos en lavaderos y talleres de planchado, manufactura de tabacos y panaderías.

Los aportes de Bunge al proyecto de Joaquín V. González fueron importantes para temas relacionados con la regulación del trabajo de los menores y las mujeres. Más determinantes fueron al establecer las condiciones de higiene y seguridad del trabajo que 
236 | Entre médicos y abogados: disputas en torno a las enfermedades profesionales...

debían imperar en ciertas industrias, cuestión retomada íntegramente en el Título XI del proyecto legislativo de 1904. La Ley Nacional del Trabajo se sirvió de los fundamentos esgrimidos por Bunge y supo traducir a un marco normativo muchas de las descripciones cualitativas que aquél había proporcionado sobre los riesgos del trabajo desde su mirada médica.

El derecho se erigía como disciplina rectora y como última palabra para dirimir aspectos de las relaciones laborales, aún en terrenos como el de los accidentes y las enfermedades profesionales, donde la profesión médica tenía mucho que decir. Esa subordinación de la medicina al derecho en lo concerniente a los accidentes de trabajo quedó patentizada en el artículo 116 del proyecto de Ley Nacional del Trabajo, que establecía la obligatoriedad de los médicos, ante un caso de accidente, de emitir certificados que indicaran que el obrero estaba incapacitado para el trabajo y cuál era su grado de invalidez, su aptitud para reanudarlo y, en caso de corresponder, constataran su muerte. Más aún, se pautaba que los médicos que no asumieran su rol auxiliador de la ley y no procurasen la emisión de los certificados establecidos en la legislación pagarían una multa que iba de cincuenta a doscientos pesos. ${ }^{4}$

Es cierto que el DNH no desarrolló una línea de continuidad a la hora de producir conocimiento sobre el vínculo estrecho entre trabajo y salud, pero, como sostiene Diego Armus, formó parte del amplio espacio en el cual la medicina consolidó su lugar en el aparato burocrático-administrativo estatal. Desde allí, el cuerpo médico se afincó en un higienismo destinado a mejorar y regular el mundo urbano y desarrolló un utillaje para la comprensión de la cuestión social, “...produciendo lo que se llamó higiene social, un corpus sobre el cual, más tarde, entre los años veinte y los cuarenta, se desarrollaría la salud pública" (Armus, 2000, p. 545).

¿Por qué a pesar de comprender que algunas industrias específicas por su naturaleza eran más nocivas, peligrosas o proclives a generar ciertas alteraciones de la salud, el cuerpo médico aún no había especificado qué se entendía por enfermedades profesionales? Es probable que la emergencia ante situaciones de accidentes laborales, que dejaban a los trabajadores en situación de "invalidez" o muerte, haya marcado la temporalidad de la agenda de prioridades. También es cierto que si bien el avance de la bacteriología desplazaba a las teorías miasmáticas, ese cambio paradigmático no se encontraba concluido y la idea de un ambiente insalubre primaba como factor explicativo de la propagación de enfermedades. ${ }^{5}$ No obstante, puede inferirse que lo que incidía en una posposición de la definición de lo que se entendía por enfermedades profesionales se emparentó con las transformaciones por las cuales estaba atravesando el marco doctrinario en

\footnotetext{
${ }^{4}$ DSCD, Tomo I, 1904, p. 109.

${ }^{5}$ Esto explica en parte por qué el trabajo a domicilio demandó una atención particular de los higienistas, quienes procuraron evitar que una misma habitación sirviera de taller, dormitorio, cocina y comedor. El trabajo a domicilio también adquirió relevancia en los análisis de la época por la gran participación que tenían en él las mujeres trabajadoras.
}

Anuario de la Escuela de Historia Virtual - Año 11 - Nº 18 - 2020: pp. 229-250. ISSN: 1853-7049 
materia de accidentes de trabajo: la aceptación del riesgo profesional como doctrina estaba aún en discusión y las voces de los jurisconsultos se centraron en ese debate. Al igual que los alcances de las indemnizaciones, el seguro obrero, el procedimiento jurídico, la definición de lo que se entendía como enfermedades profesionales aún estaba en controversia. No solo en cuanto a su inclusión dentro del marco normativo, sino también a causa de la carencia de consenso por parte de los profesionales de la medicina quienes aún mostraban incertidumbre a la hora de precisar que el origen de ciertas enfermedades era producto del ejercicio laboral. Sin dudas, estas situaciones estuvieron atravesadas por las demandas provenientes de los trabajadores que, en tanto atizaban los grados de conflictividad social, aceleraban el avance del arbitraje estatal y la fijación de canales regulatorios sobre las relaciones laborales.

La disciplina médica había detentado un lugar privilegiado en la generación de saberes sobre las condiciones de trabajo en las distintas ramas productivas y escudriñado sus efectos sobre la salud de los obreros. Ello lo había logrado en base a la inspección de los ambientes laborales, tarea en la cual los médicos aventajaron a ingenieros, juristas, estadígrafos. Sin embargo, la creación del DNT en 1907, como sostiene Victoria Haidar (2008, p. 184), significó la aparición de una institución que presentó espacios de competencia con el DNH en cuestiones relativas a la higiene pública y, particularmente, a la salud en espacios laborales. Esto provocó que la capacidad institucional de la entidad sanitaria se restringiera progresivamente en esa área de atribuciones. Si bien la mirada de los funcionarios del DNT distó de estar enraizada en un cristal médico, ${ }^{6}$ sus relevamientos incluyeron conclusiones vinculadas con las condiciones de higiene y seguridad en los espacios productivos. A partir de esto, resulta plausible inferir que el perfil jurídico predominante entre los funcionarios del DNT se tornó más favorable para acercar opiniones sobre el mundo del trabajo, en tanto el lenguaje del derecho se presentaba como el instrumento más adecuado para promover reformas en el plano social. Fundamentalmente, ello se observaba a partir de la aceptación de que tal disciplina se separaba de un posicionamiento clásico y basado en las relaciones privadas para adquirir, en cambio, una faceta regulatoria de lo público.

\section{El Departamento Nacional del Trabajo y la conformación de una idea de enfermedad profesional}

Si bien ni el proyecto de ley de accidentes de trabajo presentado por Roldán y Avellaneda en 1902, ni el proyecto de Ley Nacional de Trabajo de 1904 contaron con la aprobación legislativa, la falta de un marco regulatorio específico para los pleitos por accidentes no fue óbice para que se produjeran transformaciones en la interpretación de las responsabilidades en caso de que los trabajadores sufrieran un daño en el ejercicio de su labor.

${ }^{6}$ Como demuestra Eduardo Zimmermann (1995, pp. 72-73), la relación de José Matienzo, primer presidente del DNT, con la Facultad de Derecho y Ciencias Sociales de la Universidad de Buenos Aires, de la cual era docente, le sirvió para reclutar recursos humanos que demostraran interés en la faceta laboral del derecho.

Anuario de la Escuela de Historia Virtual - Año 11 - N 18 - 2020: pp. 229-250. ISSN: 1853-7049 
238 | Entre médicos y abogados: disputas en torno a las enfermedades profesionales...

Paulatinamente, esto fue quedando de manifiesto en los criterios jurídicos que comenzaron a vislumbrarse hacia mediados de la primera década de la centuria. Así, algunos fallos tuvieron en cuenta el principio del riesgo profesional que emergía de considerar que los accidentes no se hubieran suscitado de no mediar una tarea que, al ser llevada a cabo para un empleador, permitía la recurrencia judicial a la doctrina de la responsabilidad patronal (Schjolden, 2002).

La creación del DNT, por decreto del Presidente de la República del 14 de marzo de 1907, fijó entre sus deberes la recolección y publicación de datos que favorecieran el conocimiento de lo que acontecía en el mundo del trabajo. Ya durante las sesiones legislativas en que se discutió su creación, se insistió en que una de sus funciones sería preparar los reglamentos para ser considerados por el Poder Ejecutivo “...sobre los medios de seguridad que se requieren en previsión de accidentes, enfermedades y otros daños en las diversas industrias y géneros del trabajo, indicando los aparatos y métodos adecuados sobre la mejor clasificación de los accidentes en el sentido de facilitar las indemnizaciones". ${ }^{7}$

Desde la presidencia del Departamento, ocupada inicialmente por José Matienzo, se atendió lo normado y se comenzó una ardua tarea de recopilación de la información que, durante los primeros tiempos de funcionamiento de la entidad, fue más profusa que su función de espacio generador de saberes donde técnicos y expertos esbozaron y difundieron sus opiniones. Como rasgo característico de esa época se observó una política proclive a fundamentar las valoraciones que se hacían tomando como sustento la circulación de ideas producidas en el espacio internacional, en algunos casos adaptadas al ámbito local (Suriano, 2013). El aspecto más llamativo de la intervención del Departamento sobre los riesgos laborales fue la pronta formulación de un proyecto de ley sobre reparación de los accidentes de trabajo, que el 16 de septiembre de 1907 Matienzo elevó a su superior, el ministro del Interior Manuel Montes de Oca. Para el presidente del DNT existían factores objetivos que imponían la necesidad de sancionar una ley sobre accidentes, entre los que se encontraba que la jurisprudencia se había mostrado favorable a aceptar la doctrina del riesgo profesional y fundamentalmente en la forma en que avanzaban los marcos normativos de los países que adaptaban el derecho a las necesidades de sus incipientes industrias.

En la fundamentación que acompañó a su proyecto, Matienzo se preguntó si debían considerarse accidentes a las enfermedades adquiridas en el trabajo, y en su respuesta deslizó la primera argumentación sólida que desde el punto de vista de los saberes técnicos se alcanzó sobre el tema en el país. El presidente del DNT se detuvo en observar la ley inglesa de fines de 1906, en la cual se enumeraron las enfermedades que podían considerarse profesionales. De dicha legislación tomó la idea de asimilar enfermedad a accidente, aunque aclaró que limitaba el alcance de aquella a las enfermedades más notoriamente ocasionadas por el trabajo industrial. Para Matienzo, no había razón para dejar

${ }^{7}$ Boletín del Departamento Nacional del Trabajo (en adelante BDNT), N 1, 30 de junio de 1907, p. 6. 
sin reparación la enfermedad, ya que, si bien el deterioro de la salud del obrero era interpretado como una consecuencia inevitable de la industria, era un riesgo que debía estar a cargo del empresario. Más aún, Matienzo sostuvo que, en ciertas industrias, la enfermedad era una contingencia más probable que el accidente, lo cual fue ejemplificado con los casos de saturnismo en pintores y tipógrafos. El capítulo IV del proyecto fue dedicado a las enfermedades contraídas en el trabajo, aunque solo estuvo compuesto por un único artículo, con siete breves incisos. Allí, se definieron las enfermedades profesionales, que eran consideradas solo si aparecían como un efecto de la clase de trabajo realizado por el obrero en el último año que precedió a la inhabilitación. El catálogo incluía: ántrax, anquilostomiasis, envenenamiento por el plomo, por el mercurio, por el fósforo, por el arsénico, o por los derivados de estos, siendo atribución del Poder Ejecutivo modificar dicha nómina. ${ }^{8}$

El surgimiento del DNT significó la aparición de zonas grises entre las atribuciones de la agencia laboral y el DNH, fundamentalmente en lo que refirió a inspecciones de los establecimientos y a las condiciones de salubridad de los obreros. Esto originó algunas tensiones y disputas que paulatinamente se fueron zanjando en favor del DNT. Dos acontecimientos sobre la relación entre ambas entidades, ocurridos a los pocos meses de creada la institución laboral, son de utilidad para atender la manera en que la balanza se dirimía. En primer lugar, un decreto presidencial determinó que el doctor Carlos Roldán Verjés, médico inspector de establecimientos industriales del DNH, pasaba a prestar servicios en la agencia laboral para idéntica función. En segunda instancia, en nota del 4 de julio de 1907, Matienzo se dirigió a su par de Higiene solicitando informes acerca de las precauciones que convenía adoptar en fábricas, talleres y otros lugares de trabajo para garantizar la salud de los trabajadores, en particular de niños y mujeres, requiriendo que se indicara una nómina de las industrias más nocivas para los empleados. ${ }^{9}$

Uno de los aspectos relevantes en el funcionamiento del DNT recientemente creado fue el trabajo descriptivo de las condiciones laborales en diferentes ramas productivas y de servicios. Esas tareas fueron desarrolladas a partir de la inspección que los técnicos del Departamento realizaban en talleres e industrias, y fueron publicadas a lo largo de los distintos números del Boletín que se editaba trimestralmente. En un momento inicial, la mirada sobre los efectos perniciosos del trabajo sobre la salud de los obreros fue monopolizada por Roldán Verjés, quien firmaba los informes específicos que requerían su conocimiento profesional, o cuando se trataba de trabajos producidos en forma colectiva, se encargaba de la inspección desde el punto de vista médico. Desde su pluma hizo hincapié en los problemas de las fábricas de fósforos, donde la emanación de vapores nocivos y la manipulación de la pasta fosfórica era causante de los trastornos del fosforismo crónico que en algunos obreros se manifestaba con la afección conocida como necrosis fosforada del maxilar. La industria del vidrio fue caracterizada por el esparcimiento de

${ }^{8}$ BDNT, N² 2, 30 de septiembre de 1907, pp. 161-177.

${ }_{9}$ BDNT, N², 30 de septiembre de 1907, pp. 198-199. 
240 I Entre médicos y abogados: disputas en torno a las enfermedades profesionales...

polvos con alto contenido de sílice y de cal, cuya absorción provocaba afecciones del pulmón y calcicosis; en los obreros responsables de cargar los hornos se identificaba la presencia frecuente de eritemas ígneos en la cara y las manos, que podían derivar en dermatitis por la irritación cáustica que podía producir en la superficie cutánea, donde también estaba presente la catarata de los vidrieros y las opacidades del cristalino al insuflar el vidrio. ${ }^{10}$

Observaciones de igual índole se hicieron sobre la industria del ladrillo. En ellas se destacó que las afecciones más comunes entre los ladrilleros eran los dolores reumáticos y la sinovitis de los dedos de las manos, que se generaban a causa de tenerlas ordinariamente humedecidas por el barro al cortar el ladrillo o efectuar el montaje. A su vez, se puso de relieve que la posición de pie que se veía obligado a desarrollar el cortador, podía exponerlo a várices y a úlceras, aunque también se rescató que antiguamente este trabajo era más penoso, ya que se practicaba en el piso de la cancha y el obrero estaba en posición de flexión continua que lo exponía a coxalgias, lumbagos y neuralgias ciáticas. A lo largo de los Boletines, que se difundieron en la primera década de funcionamiento del DNT, se fue estableciendo una relación vincular entre puesto de trabajo y enfermedad profesional: se identificó a los trabajadores panaderos con su alta propensión a contraer tifus; la humedad de las curtidurías como causa de las bronquitis y disturbios gastrointestinales; los peligros del plomo en imprentas y litografías; las intoxicaciones por el uso de la cerusa entre los pintores.

Las ideas que sobre las condiciones de trabajo germinaban en el ámbito internacional repercutieron sensiblemente en los saberes de los técnicos argentinos. El desarrollo teórico producido en Europa, y particularmente en Francia, fue ponderado favorablemente en el medio local. Figuras como Jean Leclerc de Pulligny, André Chantemesse, Ernest Mosny y Paul Brouardel fueron reconocidas como voces autorizadas en relación con los estudios sobre los ambientes de trabajo. Pero su influencia más notable fue la propagación del concepto de higiene industrial, entendido como "...las medidas que se imponen para conservar la salud del obrero", y definido "...como la ciencia que estudia la preservación de la salud del personal de los establecimientos de la industria y del comercio". ${ }^{11}$ Así concebida, la higiene industrial demandaba atender la estrecha ligazón de las industrias insalubres e infectantes con las enfermedades profesionales. Desde esa óptica las condiciones de higiene corporal, la alimentación en el ambiente de trabajo y la falta de aseo de las manos de los obreros, en muchos casos producto de la falta de lavabos en las fábricas, se veía como causante del saturnismo entre los que trabajaban el plomo, hidrargirismo entre los que manipulaban el mercurio, infecciones carbuncosas entre quienes trabajaban pieles, y fosforismo crónico en las industrias en que intervenía el fósforo blanco. Las ideas sobre la salubridad laboral también circularon a partir de las actas de congresos o reuniones científicas. Entre el 8 y el 10 de abril de 1909 se desarrolló en París

${ }^{10}$ BDNT, N³, 31 de diciembre de 1907, pp. 331-332; 340-341.

${ }^{11}$ Brouardel, P. y Mosny, E. (1908). Traité d'hygiène industrielle, citada en: BDNT, Nº 6, 30 de septiembre de 1908, p. 433.

Anuario de la Escuela de Historia Virtual - Año 11 - N 18 - 2020: pp. 229-250. ISSN: 1853-7049 
el Cuarto Congreso de la Asociación Obrera para la higiene de los trabajadores y los talleres. Allí, se debatieron los problemas inherentes a la definición de las enfermedades profesionales, ya que no obstante los progresos de la medicina, no siempre era posible establecer con seguridad la relación directa entre enfermedad con la causa profesional.

Quizás, el aporte más importante del programa propuesto por la higiene industrial estribó en desarrollar métodos de trabajo y dispositivos que oficiasen favoreciendo la prevención de accidentes y enfermedades. Esto supuso una paulatina bifurcación en la incumbencia que le cabía a las profesiones para dictaminar sobre los alcances que tenía la evaluación de los ambientes laborales. Por un lado, la prevención se ligaría a mejorar los diseños de los procesos productivos en favor del resguardo de la salud de los obreros, en un camino de especialización dentro de la ingeniería que conduciría a disciplinas vinculadas a la seguridad e higiene del trabajo. Por el otro lado, las cuestiones que se ligaban a la salud en el espacio productivo continuaban en manos de los médicos, en el inicio de una trayectoria que iba a devenir en la medicina laboral.

Este escenario implicó un realineamiento en los quehaceres del DNT y del DNH en relación a sus facultades para analizar las condiciones laborales y su repercusión en la salud de los trabajadores. Tal situación estuvo atravesada por el perfil de los campos profesionales predominantes en cada una de las instituciones, entre las cuales se suscitaron nuevos espacios de competencia respecto de sus funciones. Dicho aspecto se puede rastrear en el tratamiento que los técnicos de cada entidad le dieron al tema. Por el DNH vuelve a erigirse Augusto Bunge (1909) como figura representativa de poseer un saber sobre las características de los ambientes laborales. Producto de haber sido comisionado a Europa desde fines de 1906 y por todo 1907 en "misión científica", Bunge elaboró un informe de casi 400 páginas que tituló Las conquistas de la higiene social y que se publicó en los Anales del DNH hacia mediados de 1909. Luego de analizar los problemas sociales de la miseria obrera, el médico socialista describió los peligros de la industria entre los cuales la fatiga ocupó un lugar destacado; reparó en los ambientes de trabajo, punto en el cual describió los inconvenientes que traía aparejada la falta de ventilación, los polvos en suspensión, los venenos en las industrias. Si bien los accidentes laborales y la industria a domicilio fueron abordadas, Bunge centró su informe en las enfermedades profesionales. Las caracterizó mediante la identificación de sus causas y amplió su alcance a las afecciones mentales que producía el trabajo, pero también al alcoholismo; prestó especial atención a la tuberculosis y su vínculo con los distintos procesos productivos. Para sus descripciones y argumentos, Bunge se sirvió de un conjunto de fuentes de información que, sin descuidar a los referentes franceses en el tema, se destacó por un diálogo más rico con los higienistas de origen belga, austríaco y germánico.

Desde el DNT, el enfoque sobre las condiciones de los ambientes laborales fue orientándose a registrar las inaptitudes que presentaban los espacios productivos para la seguridad de los trabajadores, con la propuesta de mejoras en la forma de llevar a cabo el proceso de trabajo y con la sugerencia de la implementación de dispositivos y mecanismos que previniesen los accidentes. Las producciones al respecto estuvieron claramente 
242 | Entre médicos y abogados: disputas en torno a las enfermedades profesionales...

representadas en la voz de Horacio Santa María, ingeniero de profesión, quien desde 1911 se erigió como la figura que atendió las condiciones de seguridad de los lugares de trabajo inspeccionados por los funcionarios del DNT. Su aporte fue central en el estudio monográfico que sobre los accidentes de trabajo publicó la entidad laboral en su Boletín número 20 del año 1912. La de Santa María, a través de su informe "Protección y seguridad contra los accidentes de trabajo", ${ }^{12}$ fue la única mirada que se realizó por fuera de la perspectiva jurídica que monopolizó el análisis desde las opiniones de los funcionarios del DNT, Alejandro Unsain, Federico Figueroa y Alejandro Ruzo, todos ellos abogados, quienes se mostraron afanosos por sostener que el derecho era la herramienta adecuada para resolver la problemática de los accidentes.

Las líneas de contacto entre las funciones del DNT y del DNH encontraron un punto álgido en las atribuciones que los organismos pretendían tener sobre la inspección de los ambientes de trabajo. Esa tensión estuvo atravesada por los alineamientos y disputas entre los campos profesionales protagónicos en cada institución. En 1911, el médico José Penna, flamante director del DNH promovió una reorganización de la entidad sanitaria con el afán de adaptarla a los nuevos tiempos. Sin duda, influenciado por las opiniones de Bunge, Penna destacó las atribuciones que tenía la higiene social y los beneficios que podía proporcionar a la regulación de la salud de los trabajadores. Como ya señaló Victoria Haidar, Bunge oficiaba de punta de lanza en la defensa de las atribuciones médicas, no solo en lo inherente a la medicalización de los cuerpos de los trabajadores, sino en lo concerniente a la inspección médico-sanitaria de los establecimientos. Bunge sostenía que solo los médicos podían apreciar las alteraciones que en la salud de los obreros generaba su desempeño laboral. En ese sentido, a su entender, la facultad para realizar inspecciones laborales debía ser comandada por los profesionales médicos del DNH.

En 1912, la sanción de la Ley orgánica del DNT ( ${ }^{\circ}$ 8.999) determinó que la institución quedaba constituida en tres secciones: legislación, estadística e inspección y vigilancia. Siguiendo a Germán Soprano, es posible afirmar que, en la definición de su proyecto institucional, la agencia laboral fue afirmando su autonomía y la de su funcionariado respecto de otros organismos estatales y de otros actores (Soprano, 2010, p. 112). Al mismo tiempo, Soprano destaca que las atribuciones de la inspección permitieron una diferenciación respecto de las facultades que poseían otros ámbitos estatales, como el DNH y la Policía. Sin embargo, esa separación no se dio en base a una relación de igualdad, sino de imposición normativa que la entidad laboral hacía sobre la sanitaria, ambas dependientes del mismo Ministerio del Interior. El decreto reglamentario de la ley $\mathrm{N}^{\circ}$ 8.999 promulgado en enero de 1913 fijó en sus disposiciones generales cómo se daría la relación entre el DNT y el DNH. En el artículo 37 se facultaba al DNT a solicitar al DNH inspecciones técnicas en establecimientos industriales y comerciales para asegurar el cumplimiento de la ley que regulaba el trabajo de mujeres y niños, en lo que atañía a las condiciones higiénicas de los locales y a la salud de los obreros; los resultados de esas

${ }^{12}$ BDNT, N 20, 31 de julio de 1912, pp. 225-295.

Anuario de la Escuela de Historia Virtual - Año 11 - N 18 - 2020: pp. 229-250. ISSN: 1853-7049 
inspecciones y las medidas que el DNH consideraba que se debían implementar para garantizar la efectividad de la ley debían ser comunicadas por escrito al DNT. No obstante, en el artículo 38 se estableció que los inspectores del DNH recibirían autorización del presidente del DNT para hacer la visita a los establecimientos. En lo concerniente a las enfermedades profesionales, en el artículo 40 del mencionado reglamento, el DNT se arrogó la facultad de solicitar al DNH inspecciones de los establecimientos donde se efectuaban trabajos capaces de producirlas. ${ }^{13}$ En el sentido de lo expuesto es plausible sostener que las relaciones entre el DNT y el DNH quedaron reglamentadas en forma asimétrica, en tanto la intervención de la agencia sanitaria se producía solo a partir de la demanda del ámbito laboral. Así todo, también resulta cierto que se reconocía en el DNH la pertinencia profesional de intervenir en lo que tenía que ver con los criterios médicos.

\section{La regulación de las enfermedades profesionales: los debates en el camino a la sanción de la ley $N^{\circ} 9.688$}

En la década que precedió a la sanción de la ley Nº 9.688 de 1915 se elevaron diversos proyectos legislativos con la finalidad de establecer un marco regulatorio sobre los accidentes y enfermedades del trabajo. Una serie de elementos oficiaron para que se sancionase la normativa: la manera en que evolucionaba el derecho en el extranjero, legislando los accidentes en base a la doctrina del riesgo profesional; los adeptos que dicha doctrina iba alcanzando dentro del marco jurídico local, asentando una jurisprudencia que adquiría lejanía respecto de la doctrina de la culpa; las opiniones de técnicos y políticos favorables a la necesidad de contar con un resguardo legal para los casos de accidentes laborales. Estos aspectos aglutinaron, en cierta medida, a causa de lo que en la época la prensa periódica llamó "La catástrofe del Riachuelo", ${ }^{14}$ dando lugar a la sanción de la ley $\mathrm{N}^{\circ} 9.085$ que indemnizaba a los trabajadores lesionados y a las familias de los fallecidos, oficiando de prolegómeno a la ley de accidentes que se aprobaría dos años después. Más allá que las voces favorables a la sanción de una ley reparadora de los accidentes contasen con el beneplácito de sectores tan opuestos como la Unión Industrial Argentina y el partido socialista, su promulgación se dilató en el tiempo y suscitó la presentación de diversos proyectos legislativos en el recinto parlamentario. Una lectura de esas manifestaciones procura reponer en forma sintética cuál era la mirada de diputados y legisladores sobre las enfermedades profesionales y qué relación existía -si es que la había- con los saberes que médicos y abogados generaban en los ámbitos estatales representados en el DNH y el DNT.

Además de los proyectos legislativos que fueron llevados al Congreso por Avellaneda

\footnotetext{
${ }^{13}$ BDNT, $N^{\circ} 23,1913$, pp. 57-58.

${ }^{14}$ Las publicaciones periódicas de la época denominaron "Catástrofe del Riachuelo" a la explosión de dos gasómetros llenos de acetileno instalados en los talleres del Ministerio de Obras Públicas en la Boca del Riachuelo, en los límites de la Capital Federal y la ciudad de Avellaneda. El accidente, acontecido el 23 de mayo de 1913, produjo la muerte de trece trabajadores y muchos otros sufrieron heridas graves.
}

Anuario de la Escuela de Historia Virtual - Año 11 - No 18 - 2020: pp. 229-250. ISSN: 1853-7049 
244 | Entre médicos y abogados: disputas en torno a las enfermedades profesionales...

y Roldán -1902- y por Joaquín V. González -1904-, en 1907, el Partido Socialista por intermedio del diputado Alfredo Palacios presentó un proyecto para regular las indemnizaciones en caso de accidentes. El mismo trasladó a los patrones la responsabilidad indemnizatoria en caso de enfermedades graves producto de la relación entre el ambiente laboral y el trabajador. En 1912, nuevamente Palacios, ahora junto a los diputados Juan B. Justo y al radical Eduardo Laurencena, elevaron un proyecto que fijaba que, además de las enfermedades agudas, las intoxicaciones crónicas que podían producir ambientes de trabajo nocivos a la salud de los obreros también otorgaban a los trabajadores el derecho a percibir una indemnización. Pero esta inclusión de las enfermedades profesionales como tema a ser regulado por la legislación no fue solo obra del socialismo. En 1910, el diputado Adrián Escobar también hizo alusión a la regulación de las indemnizaciones de las enfermedades que eran producidas por el trabajo, e incluyó un concepto original al incluir las lesiones intelectuales como equiparables a los accidentes repentinos. La propuesta de Escobar facultaba al Poder Ejecutivo a determinar la nómina de enfermedades que debían derivar en una indemnización a favor del trabajador. Igual tratamiento a las enfermedades profesionales dio el diputado Arturo Bas en su iniciativa de 1914.

Distinta fue la opinión esbozada por Rogelio Araya, diputado perteneciente a la Unión Cívica Radical, en la presentación del proyecto elevado a la Cámara Baja en 1912, ya que, si bien también incluyó a las enfermedades como originadoras de una acción indemnizatoria, se sirvió de precisar cuáles eran aquellas. Para ello, amplió brevemente la nómina que cinco años atrás había elaborado José Matienzo desde el DNT. Así, las enfermedades que para Araya debían habilitar canales para la reparación por la vía indemnizatoria eran ántrax, anquilostomiasis, envenenamiento por el plomo, fósforo, mercurio, arsénico, y sus derivados, o toda otra que el Poder Ejecutivo consignare. ${ }^{15} \mathrm{El}$ texto elaborado por Araya preveía la constitución de un cuerpo médico al interior del DNT, que serían los encargados de redactar los certificados que acompañarían las denuncias por accidentes, estudiar las enfermedades profesionales y recomendar métodos de prevención de accidentes y mejoras de las condiciones de higiene y salud en el ambiente de trabajo. A diferencia de las presentaciones parlamentarias que lo precedieron, Araya otorgó centralidad a la profesión médica reivindicando las facultades que le correspondían a la disciplina para intervenir en materia de validación de cuestiones que eran inherentes a sus saberes.

A lo largo de la gran cantidad de proyectos relacionados con la necesidad de regular los accidentes se pudo ver que las enfermedades laborales serían contempladas de forma inexorable como equivalente de la lesión física repentina. La contribución de los técnicos del DNT a la hora de documentar las condiciones de trabajo y los peligros que ciertas industrias, por su naturaleza, producían sobre la salubridad de los obreros, no fue desatendida en el ámbito legislativo, que pareció acordar de forma unánime en considerar

${ }^{15}$ DSCD, Tomo I, Año 1914, 22 de julio, p. 181.

Anuario de la Escuela de Historia Virtual - Año 11 - N 18 - 2020: pp. 229-250. ISSN: 1853-7049 
a las enfermedades con un tratamiento similar al de los accidentes. Esta posición de los legisladores nacionales estuvo vinculada a una vocación por otorgarle un carácter vanguardista a la norma, que la pusiera en sintonía con las novedosas experiencias foráneas. A fines de septiembre de 1915 se inició el debate en la Cámara de Diputados de la Nación que devendría en la sanción de la ley $\mathrm{N}^{\circ}$ 9.688, y ya nadie puso reparo a la hora de incorporar a las enfermedades profesionales dentro de las causales indemnizatorias. Más aún, en alocuciones como las del diputado socialista Nicolás Repetto, también médico, se asignó a la enfermedad profesional una valoración mayor que al accidente, ya que se consideró que la primera fase de este era justamente una enfermedad; de allí sustentó la idea de crear un seguro contra las enfermedades, que fusionado con el de accidentes, diera origen a un seguro social. ${ }^{16}$

Finalmente, la sanción de la ley $N^{\circ} 9.688$ incorporó en su Artículo 22 el tratamiento de las enfermedades profesionales, que para ser tales debían ser contraídas en el ejercicio de la profesión durante el año precedente a la inhabilitación para trabajar. Mientras otros artículos del proyecto legislativo tratado en comisión fueron discutidos acaloradamente, el que incorporó las enfermedades profesionales en el marco de la ley no sufrió ninguna propuesta de rectificación y se aprobó sin discusión.

En la ley se previó que las enfermedades profesionales debían ser taxativamente enumeradas por el Poder Ejecutivo a través de los decretos que reglamentaran la norma. Cuando en enero de 1916 se sancionó el decreto reglamentario de la ley $N^{\circ} 9.688$ de Responsabilidad por Accidentes del Trabajo, en su Artículo 149 se especificó la nómina de las enfermedades profesionales que hasta ese momento se consignaron a los efectos del Art. 22 de la Ley: Pneumoconiosis; tabacosis pulmonar; antracosis; siderosis; saturnismo; hidrargirismo; cuprismo; arsenicismo; oftalmía amoniacal; sulfocarbonismo; hidrocarburismo; fosforismo; infección carbuncosa; dermatosis; anquilostomiasis; brucelosis; trastornos patológicos debidos al radio y demás sustancias radiactivas y a los rayos $\mathrm{X}$ y los epiteliomas primitivos de la piel, originados por la manipulación de alquitrán, la brea, el betún, aceites minerales, parafina o compuestos, productos o residuos de estas sustancias y el calambre profesional del telegrafista o neuromiotrauma eléctrico. De esa manera, el decreto que reglamentó la ley $\mathrm{N}^{\circ} 9.688$ estuvo dotado de un sentido moderno en tanto ofició de colector de la gran mayoría de las enfermedades que, en el concierto internacional, se consideraban producidas por ciertas actividades laborales. Por ello, fue mucho más amplio que las propuestas precedentes en cuanto a las enfermedades profesionales que se contemplaron, probablemente porque su finalidad en el corto plazo tuvo un viso más político que práctico, en razón de las dificultades que se les presentaban a los trabajadores para demostrar parentesco entre enfermedad y tarea desempeñada. Así todo, enfermedades como la tuberculosis, ${ }^{17}$ la hidatidosis, paludismo, enfermedades car-

\footnotetext{
${ }_{16}$ DSCD, Año 1915, p. 560.

${ }^{17}$ Diego Armus (2007, p. 188) sostiene que los especialistas de la época discutieron si la tuberculosis era una enfermedad profesional y terminaron reconociendo que esa definición era problemática en tanto existían
}

Anuario de la Escuela de Historia Virtual - Año 11 - N 18 - 2020: pp. 229-250. ISSN: 1853-7049 
246 | Entre médicos y abogados: disputas en torno a las enfermedades profesionales...

diovasculares, y las vinculadas al uso de ácido muriático quedaron por fuera de la cobertura legal, con lo cual enfermedades frecuentes en determinados trabajos rurales, urbanos y vinculados a las tareas domésticas, ${ }^{18}$ no generaban derecho a la percepción indemnizatoria.

Desconocemos quiénes colaboraron en la confección de aquella nómina, aunque es posible que se hayan recogido las experiencias que los médicos, juristas e ingenieros fueron registrando en sus informes durante los años anteriores a 1915. El reconocimiento explícito de los parlamentarios hacia los saberes técnicos generados por los funcionarios del DNT fue escaso, aunque peor suerte corrieron los miembros del DNH, cuya contribución se sumió en la invisibilidad. Ello puede explicarse a partir de dos aspectos. Por un lado, que los diálogos entre los legisladores y los funcionarios del DNT se hacían en un idioma común, el del derecho, que facilitó el tendido de lazos entre ambas instituciones. Por el otro lado, que la presencia de diputados socialistas de profesión médica no necesitara enunciar un vínculo disciplinar con la medicina, en tanto era una cuestión de por sí reconocida por la audiencia.

\section{A modo de balance}

A principios del siglo XX, el conocimiento inherente a temas vinculados con los accidentes de trabajo emergió de diversos campos profesionales. La relación entre condiciones adversas del ambiente laboral y el deterioro de la salud de los obreros había sido puesta en evidencia por los higienistas argentinos de las últimas décadas del ochocientos. Pero fue durante los años que rondaron al cambio de centuria cuando las preocupaciones relacionadas con la cuestión social influyeron en la producción de saberes que se orientaron a atemperar los problemas emergentes, muchos vinculados a las transformaciones que se producían en las relaciones laborales. La medicina, de la mano de Augusto Bunge, hizo aportes considerables para argumentar desde el punto de vista científico, que existía una relación directa entre trabajo y salud. De ello da muestras El trabajo industrial en Buenos Aires, informe que en 1904 produjo Bunge dentro de la órbita del DNH, y bajo el encuadre del entonces ministro del Interior, Joaquín V. González. Este último buscaba insumos para su pretendido código de trabajo por el cual, mediante las herramientas normativas que proporcionaba el derecho, promovía una regulación de las relaciones laborales. Desde esos primeros intentos regulatorios, el campo médico quedó postergado a oficiar de disciplina de apoyo a las necesidades del derecho, en tanto eran los juristas quienes definían los alcances y limitaciones que tenían las atribuciones de los

numerosas causas que determinaban su aparición. Recién en 1936, por decreto del Poder Ejecutivo que amplió la lista de enfermedades profesionales, se otorgó cobertura indemnizatoria a los obreros que sufrían de tuberculosis producto de su trabajo.

${ }^{18}$ Débora Garazi (2017, pp. 167-170) hace referencia a la invisibilidad que tenían ciertas enfermedades profesionales ligadas al trabajo doméstico, ámbito mayoritariamente femenino, en los presupuestos culturales que reinaron a lo largo del siglo XX. Estos postulados recién comenzaron a revertirse durante la década de 1990 cuando estudios médicos demostraron que las tareas domésticas a gran escala generan daños físicos.

Anuario de la Escuela de Historia Virtual - Año 11 - Nº 18 - 2020: pp. 229-250. ISSN: 1853-7049 
médicos a la hora de zanjar discusiones sobre accidentes y enfermedades profesionales. La creación y puesta en funciones del DNT en 1907 irrumpió en una serie de aspectos que realinearon las idoneidades de médicos y abogados en materia de accidentes y enfermedades. En primer lugar, el DNT generó un espacio de competencia respecto de las atribuciones hasta entonces exclusivas del DNH, fundamentalmente en las tareas de inspección de las condiciones de trabajo. En segundo lugar, la producción de saberes por parte de los técnicos del DNT incorporó la estrategia de poner los ojos en la legislación comparada, donde el estudio de lo que ocurría en otros países fue central. En tercer lugar, el pasaje del doctor Roldán Verjés, médico que ejercía funciones en el DNH, a desempeñarse en el DNT como inspector de establecimientos industriales, significó una aceptación de parte del Ministerio del Interior, del cual dependían ambas agencias, de que las miradas sobre la salud de los trabajadores en sus puestos laborales se correspondían con atribuciones de la institución laboral.

Desde el DNT fueron prolíficas las contribuciones a la descripción de las condiciones de trabajo. Distintas industrias y comercios fueron visitados y se recopiló en cada uno un detalle de los efectos del trabajo sobre la salud. Empezaron así a establecerse relaciones entre cada puesto de trabajo y las posibles enfermedades profesionales que podían generar. Una vez más, las ideas que se debatían en los espacios internacionales dedicados a regular las condiciones laborales, fueron tomadas en Argentina. El concepto de higiene industrial se incluyó como fuente de inspiración local a partir de la lectura de autores franceses, y de las resoluciones que se tomaban en congresos internacionales abocados al tema. La definición de las enfermedades profesionales adquiría precisión. También la higiene industrial aportó a la hora de desarrollar métodos y dispositivos que previniesen la proliferación de accidentes y de enfermedades. Horacio Santa María, desde el DNT, desarrolló una línea de trabajo en ese sentido a partir de 1911, y desde su profesión de ingeniero realizó contribuciones al diseño de los procesos industriales para disminuir los efectos del trabajo en la salud de los obreros.

El DNT parecía así acaparar funciones relacionadas con la mirada médica que sobre los espacios de trabajo había detentado el DNH. Sin embargo, nuevamente la figura de Augusto Bunge se erigió en defensa de las facultades de su disciplina médica sobre la inspección médico-sanitaria de los establecimientos y sobre la potestad que debía tener el DNH en ese sentido. En 1912, la sanción de la Ley orgánica del DNT vino a poner un manto de claridad entre esas tensiones interdepartamentales. En esa norma se facultó a la agencia laboral a realizar tareas de inspección, pero también se detallaron las relaciones que esta tendría con su par sanitaria. La asimetría era evidente en favor de las facultades del DNT, en tanto la intervención del DNH se realizaba a solicitud de aquella. No obstante, allí se reconoció la pertinencia profesional de los médicos para dirimir aspectos de la salud obrera, y el ámbito estatal desde el cual ello se realizaría era el DNH. Estas disputas no hicieron mella en el debate parlamentario. A pesar de ello, es posible sostener que en la sanción de la ley de accidentes y más aún en su decreto reglamentario, los saberes generados por médicos, abogados e ingenieros oficiaron complementariamente 
248 | Entre médicos y abogados: disputas en torno a las enfermedades profesionales...

y colaboraron en precisar los alcances de la nueva legislación.

Existieron así ámbitos de competitividad y tensiones entre las incumbencias profesionales que se atribuía cada disciplina para intervenir en materia de accidentes de trabajo y fundamentalmente en definir el alcance del concepto de enfermedades profesionales. La medicina pudo sufrir el embate de los juristas en su pretensión de pautar las relaciones laborales en una lógica casi exclusiva del derecho. Aunque tuvo que reducir su ámbito de aplicación desde una mirada integral de las condiciones laborales a los efectos que estos podían generar en la salud, siguió siendo una fuente de consulta inexorable para certificar los daños que el trabajo podía generar en los obreros. Las herramientas de que disponía el derecho parecían las más adecuadas para regular los accidentes, y la exhaustividad con que se reglamentó la ley $\mathrm{N}^{\circ} 9.688$ asemejó una pretensión por dejar bajo su órbita disciplinar las facultades para dirimir los litigios que tal problemática del mundo laboral podía originar.

\section{Referencias bibliográficas}

Armus, D. (2000). El descubrimiento de la enfermedad como problema social. En M. Z. Lobato (Ed.), El Progreso, la modernización y sus límites. Nueva Historia Argentina (pp. 507-551). Buenos Aires: Sudamericana.

Armus, D. (2007). La ciudad impura. Salud, tuberculosis y cultura en Buenos Aires, 1870-1950. Buenos Aires: Edhasa.

Biernat, C. y Ramacciotti, K. (2013). Crecer y multiplicarse. La política sanitaria materno infantil, Argentina 1900-1960. Buenos Aires: Biblos.

Bohoslavsky, E. y Soprano, G. (2010). Una evaluación y propuestas para el estudio del Estado en Argentina. En E. Bohoslavsky y G. Soprano (Eds.), Un estado con rostro humano. Funcionarios e instituciones estatales en Argentina (desde 1880 a la actualidad) (pp. 9-55). Buenos Aires: Prometeo/Universidad Nacional de General Sarmiento.

Bunge, A. (1904). El trabajo industrial en Buenos Aires. Anales del Departamento Nacional de Higiene, IX (5), 339-364.

Bunge, A. (1909). Las conquistas de la higiene social. Anales del Departamento Nacional de Higiene, $\mathrm{V}$ al X.

Fiquepron, M. (2017). Los vecinos de Buenos Aires ante las epidemias de cólera y fiebre amarilla (1856-1886). Quinto Sol, 21 (3), 1-22.

Galeano, D. (2009). Médicos y policías durante la epidemia de fiebre amarilla (Buenos Aires, 1871). Salud Colectiva, 5 (1), 107-120.

Garazi, D. (2017). Trabajo, género y servicios: experiencias y representaciones del trabajo en la hotelería. Mar del Plata, segunda mitad del siglo XX (Tesis de Doctorado). Universidad Nacional de Quilmes, Bernal.

Golbert, L. (2010). De la sociedad de Beneficencia a los Derechos Sociales. Buenos Aires: Ministerio de Trabajo, Empleo y Seguridad Social de la Nación.

González Leandri, R. (2010). Breve historia del Departamento Nacional de Higiene. Estado, gobernabilidad y autonomía médica en la segunda mitad del siglo XIX. En E. 
Bohoslavsky y G. Soprano (Eds.), Un Estado con rostro humano. Funcionarios e instituciones estatales en Argentina (desde 1880 hasta la actualidad) (pp. 59-85). Buenos Aires: Prometeo/Universidad Nacional de General Sarmiento.

González Leandri, R. (2013). Internacionalidad, Higiene y Cuestión Social en Buenos Aires (1850-1910). Tres momentos históricos. Revista de Indias, LXXIII (257), 81-106.

González Leandri, R. (2017). Contribuciones de la prensa médica al diagnóstico de la Cuestión Social. Buenos Aires (1870-1910). En R. González Leandri y J. Suriano (Eds.), La cuestión social y sus itinerarios de difusión a través de las publicaciones periódicas argentinas, 1870-1930 (pp. 25-48). Columbia: Global South Press.

González Leandri, R. y Suriano, J. (2017). Introducción. En R. González Leandri y J. Suriano (Eds.), La cuestión social y sus itinerarios de difusión a través de las publicaciones periódicas argentinas, 1870-1930 (pp. 9-22). Columbia: Global South Press.

Haidar, V. (2008). Trabajadores en riesgo. Una sociología histórica de la biopolítica de la población en Argentina (1890-1915). Buenos Aires: Prometeo.

Isuani, A. (1985). Los orígenes conflictivos de la seguridad social en la Argentina. Buenos Aires: Centro Editor de América Latina.

Lobato, M. (2007). Historia de las trabajadoras en la Argentina (1869-1969). Buenos Aires: Edhasa.

Lobato, M. Z. y Suriano, J. (2014). Trabajo, cuestión social e intervención estatal. En M. Z. Lobato y J. Suriano (Comps.), La Sociedad del Trabajo. Las instituciones laborales en la Argentina (1900-1955) (pp. 5-56). Buenos Aires: Edhasa.

Maddalena, P. (2019). Los saberes estatales en Argentina: el camino a la sanción de la ley de accidentes de trabajo de 1915 (Tesis de Maestría). Instituto de Altos Estudios Sociales, Universidad Nacional de San Martín, Buenos Aires.

Maddalena, P. y Ramacciotti, K. (2019). ¿Mejor prevenir que indemnizar? Los accidentes de trabajo en Argentina, 1915-1955. Dynamis, 39 (2), 311-334.

Morresi, S. y Vommaro, G. (2011). Introducción. Los expertos como dominio de estudio socio-político. En S. Morresi y G. Vommaro (Comps.), Saber lo que se hace. Expertos y política en la Argentina (pp. 9-41). Buenos Aires: Prometeo/Universidad Nacional de General Sarmiento.

Nari, M. (2004). Políticas de maternidad y maternalismo político. Buenos Aires: Biblos.

Panettieri, J. (1984). Las primeras leyes obreras. Buenos Aires: Centro Editor de América Latina.

Ramacciotti, K. (2014). ¿Soldados del trabajo o ciudadanos? La ley de accidentes de trabajo en la Argentina, 1915-1955. En M. Z. Lobato y J. Suriano (Comps.), La Sociedad del trabajo. Las instituciones laborales en la Argentina (1900-1955) (pp. 293-317). Buenos Aires: Edhasa.

Ramacciotti, K. (2019). Los accidentes laborales en perspectiva histórica. Los Polvorines: Universidad Nacional de General Sarmiento.

Scheinkman, L. (2015). Sujetos, instituciones y derechos en la implementación de la Ley de Accidentes del Trabajo en la ciudad de Buenos Aires (1915-1922). Estudios Sociales, $49,125-154$.

Schjolden, L. (2002). Suing for Justice: Labor and the Courts in Argentina, 1900-1943. Berkeley: University of California Press.

Schjolden, L. (2009). Sentencing the Social Question: Court-Made Labour Law in Cases of Occupational Accidents in Argentina, 1900-1915. Journal of Latin American Studies, $41(1), 91-120$.

Anuario de la Escuela de Historia Virtual - Año 11 - No 18 - 2020: pp. 229-250. ISSN: 1853-7049 
250 | Entre médicos y abogados: disputas en torno a las enfermedades profesionales...

Skocpol, T. (1989). El Estado regresa al primer plano: estrategias de análisis en la investigación actual. Zona abierta, 50, 71-122.

Soprano, G. (2010). “Haciendo inspección”. Un análisis del diseño y aplicación de la inspección laboral por los funcionarios del Departamento Nacional del Trabajo (19071914). En E. Bohoslavsky y G. Soprano (Eds.), Un estado con rostro humano. Funcionarios e instituciones estatales en Argentina (desde 1880 a la actualidad) (pp. 85-120). Buenos Aires: Prometeo/Universidad Nacional de General Sarmiento.

Stagnaro, A. (2016). La Ley de Accidentes del Trabajo y los debates promovidos para la creación de un fuero laboral (Argentina, 1904-1946). Estudios Sociales, 50, 111-143.

Suriano, J. (2000). Introducción: una aproximación a la definición de la cuestión social en Argentina. En J. Suriano (Comp.), La cuestión social en Argentina, 1870-1943 (pp. 1-29). Buenos Aires: La Colmena.

Suriano, J. (2013). El mundo como un taller de observación. La creación del Departamento Nacional del Trabajo y las influencias internacionales. Revista de Indias, LXXIII (257), 107-130.

Wilde, E. (1885). Curso de Higiene Pública. Buenos Aires: Imprenta y Librería de Mayo.

Zimmermann, E. (1995). Los liberales reformistas. La cuestión social en la Argentina, 18901916. Buenos Aires: Sudamericana.

Zimmermann, E. (2013). "Un espíritu nuevo": la cuestión social y el Derecho en la Argentina (1890-1930). Revista de Indias, LXXIII (257), 81-106.

Para citar este artículo:

Maddalena, Pablo Daniel (2020). Entre médicos y abogados: disputas en torno a las enfermedades profesionales en Argentina, 1900-1915. Anuario de la Escuela de Historia Virtual, 18, 229-250. 